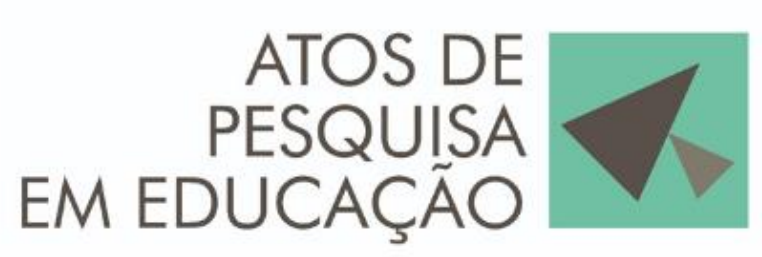

\title{
A ATUAÇÃO DO COORDENADOR PEDAGÓGICO DA REDE SESI-SP NA FORMAÇÃO DOCENTE: A CONCEPÇÃO DOS PROFESSORES
}

\author{
THE PEDAGOGICAL COORDINATOR PERFORMANCE IN THE SESI-SP \\ NETWORK IN TEACHING TRAINING: THE TEACHERS CONCEPTION
}

\section{LA ACCIÓN DEL COORDINADOR PEDAGÓGICO DE LA RED SESI-SP EN LA FORMACIÓN DOCENTE: EL DISEÑO DE LOS PROFESORES}

\author{
MIRANDA, Nonato Assis de \\ mirandanonato@uol.com.br \\ USCS - Universidade Municipal de São Caetano do Sul \\ https://orcid.org/0000-0001-6592-3381 \\ GUILHERMONI, Fernanda Dias \\ fernandaguilhermoni@gmail.com \\ USCS - Universidade Municipal de São Caetano do Sul \\ SESI SP - Serviço Social da Indústria \\ https://orcid.org/0000-0002-4053-9153
}

\begin{abstract}
RESUMO: Esta pesquisa de natureza qualitativa buscou investigar se a atuação do coordenador pedagógico (CP) na Rede SESI-SP de Ensino atende às necessidades formativas de seus docentes. Os dados foram coletados com professores de quatro escolas da Rede SESI localizadas no município de Santo André (SP). Os dados (depoimentos dos professores) foram agrupados, categorizados e analisados na perspectiva da análise de conteúdo. Em geral, os resultados mostraram que a atuação do $\mathrm{CP}$ atende parcialmente às necessidades formativas dos docentes. Dentre outros resultados, a pesquisa revela a importância de o CP atuar como parceiro e apoiador e não somente como um agente de averiguação de tarefas e que a formação pautada na concepção de ensino adotada pelo SESI permite a troca de experiência entre professores e oportuniza uma formação mais significativa.
\end{abstract}

Palavras chave: Coordenador pedagógico. Formação docente. Serviço Social da Indústria.

ABSTRACT: This qualitative research aimed to investigate if the performance of the
pedagogical coordinator (PC) in the SESI-SP Education Network meets the
educational needs of its teachers. The data were collected from teachers of four SESI
schools located in Santo André (SP). The data (teachers' statements) were grouped,
categorized and analyzed from the perspective of content analysis. In general, the
results showed that the performance of the PC partially meets the educational needs
of teachers. Among other things, the research reveals the importance of the PC acting
as a partner and supporter and not only as a task finding agent and that the training 


\section{ATOS DE \\ PESQUISA

ISSN: 1809-0354

2

based on the teaching conception adopted by SESI allows the exchange of experience among teachers and provides an opportunity for training. most significant.

Keywords: Industry Social Service. Pedagogical coordinator. Teacher training.

RESUMEN: Esta investigación cualitativa tenía como objetivo investigar si el desempeño del coordinador pedagógico (PC) en la Red de Educación SESI-SP satisface las necesidades educativas de sus maestros. Se recopilaron datos de maestros de cuatro escuelas SESI ubicadas en Santo André (SP). Los datos se agruparon, categorizaron y analizaron desde la perspectiva del análisis de contenido. En general, los resultados mostraron que el rendimiento de la PC satisface parcialmente las necesidades educativas de los maestros. Entre otras cosas, la investigación revela la importancia de que lo PC actúe como socio y apoyo y no solo como un agente de búsqueda de tareas, y que la capacitación basada en la concepción docente adoptada por SESI permite el intercambio de experiencias entre los maestros y brinda una oportunidad de capacitación. más significativo

Palabras clave: Coordinador pedagógico. Formación del profesorado. Servicio social de la industria.

\section{INTRODUÇÃO}

Este artigo se insere em uma pesquisa realizada em um Programa de PósGraduação em Educação de uma Universidade Municipal do $A B C$, que investigou as concepções de professores da Rede SESI-SP de Ensino acerca da formação desenvolvida pelo Coordenador Pedagógico (CP). A pesquisa foi motivada pelo fato de que, há algum tempo, tem-se questionado sobre a atuação do CP como formador de formadores, de modo especial na formação contínua dos professores, considerando-os como articuladores essenciais nas transformações da prática educacional.

É sabido que, na realidade da maioria das escolas, a formação contínua não se constitui como uma prática consolidada. Ao contrário, constata-se, em grande parte das instituições, professores paralisados em práticas antigas e sem um direcionamento efetivo e eficiente para mudanças de pensamento e postura em suas práticas. Embora Garrido (2008) proponha, nesse caso, que o CP proporcione e organize reflexões, junto aos professores, sobre suas ações e dificuldades que surgem no desenvolvimento da função, possibilitando uma análise sobre a prática docente e sobre o contexto escolar, esse profissional dedica a maioria da sua rotina a atribuições de caráter burocrático não atuando, portanto, como formador. 


\section{ATOS DE \\ PESQUISA \\ EM EDUCAÇÃO}

ISSN: 1809-0354

3

$\mathrm{O} \mathrm{CP}$, além de defrontar-se com o cenário escolar, também é visto como o responsável pela formação continuada dos professores, especialmente nos dias atuais, em que se exige desses profissionais conhecimentos que extrapolam o adquirido na sua formação inicial, como conhecimento tecnológico, habilidade para fazer uma avaliação diagnóstica dos estudantes, pesquisa sobre as novas metodologias. Enfim, ações que garantam que o processo de ensino e aprendizagem seja realizado com sentido e significado para o aprendiz. Reforça-se a relevância do CP diante tanto da incapacidade de formação de professores apenas através do curso de licenciatura quanto do aprofundamento dos seus estudos para a realização de um trabalho consciente, por meio, na maioria das vezes, da autoformação que Ihe traga um movimento de ação-reflexão-ação permanente.

Sobre o desenvolvimento da formação continuada dos professores, Azevedo e Alves (2004) entendem que essa formação ocorre em dois contextos, quais sejam: cursos de formação (atualização, especialização e pós-graduação) e cursos oferecidos nas redes públicas de ensino (estaduais e municipais). Tal investimento, no entanto, não é traduzido em resultados bem avaliados.

De qualquer forma, Serpa e Lopes (2011) destacam que a formação continuada pode acontecer a partir de diversos modelos (individual, em grupo, colaborativa). Entretanto, deve estar articulada às demandas da escola e/ou da educação, considerando as principais necessidades da realidade escolar. O CP, nesse caso, deve mediar e direcionar a formação dos professores para que essa ocorra no sentido de solucionar e/ou minimizar as dificuldades que a escola possui, buscando uma educação emancipatória e transformadora, com foco no aprendizado do estudante.

Segundo Placco (1994), para que a educação emancipatória se efetive, faz- se necessário o trabalho em equipe, de forma a refletir sobre o que precisa garantir-se no processo de ensino e de aprendizagem, cujo foco é repensar sobre o ambiente escolar em que a prática docente está sendo vivenciada. Nesse sentido, a fim de exercer a função de formador, o CP precisa desenvolver saberes (pedagógicos, curriculares, educacionais), que nem sempre coincidem com aqueles da sua origem profissional.

Através do acompanhamento qualitativo da prática docente, será possível diagnosticar as potencialidades e os desafios educacionais que impactam na 


\section{ATOS DE \\ PESQUISA \\ EM EDUCAÇÃO}

ISSN: 1809-0354

aprendizagem, convertendo-os em estratégias de ação formativa, propondo metas, tanto para a evolução docente quanto para a aprendizagem discente, auxiliando, assim, em um plano de ação para a melhoria do desempenho. Dessa maneira, ser gestor do processo de ensino e aprendizagem implica em gerir a forma como a proposta educacional da unidade escolar, ou da rede de ensino, se concretiza em sala de aula e nos seus resultados, cujo CP, assim como o Diretor Escolar e os professores, se corresponsabilizam pela qualidade do ensino que ocorre na escola.

\section{UM OLHAR PARA A TRAJETÓRIA DA FORMAÇÃO DE PROFESSORES}

Apesar de os primeiros ensaios relativos à formação de professores no Brasil datarem do primeiro quarto do século XIX, culminando nas Escolas Normais, de modo mais efetivo, tal prática se efetiva somente a partir da década de 1930 com a criação dos Institutos de Educação (SAVIANI, 2009). A intenção desses institutos era superar as fragilidades presentes nas Escolas Normais até então presentes "[...] sustentando seu currículo em perspectivas teórico-científicas amparadas em pesquisas, avançando em concepções pedagógico-didáticas." (GATTI et al., 2019, p. 22).

Como as Escolas Normais eram voltadas para a formação de professores para o exercício no então ensino primário, o secundário foi privilegiado somente no final da década de 1930 com a criação das licenciaturas e do curso de Pedagogia. Contudo, esse curso focou na formação do especialista em educação (bacharelado) e professores para atuar nas Escolas Normais cujo modelo ficou conhecido como $3+1$ que consistia em três anos de especialização e apenas um voltado para a formação de professores (GATTI et al. 2019).

Sumariamente, as Escolas Normais que foram agregadas ao ensino médio, desenvolveram um papel importante na formação de professores no Brasil até a aprovação da Lei no 9.394/1996 (Lei de Diretrizes e Bases da Educação) que instituiu a formação de professores em nível superior (GATTI et al., 2019). Com isso, buscouse extinguir, aos poucos, a formação de professores em nível médio, mas isso não se concretizou definitivamente, pois "[...] o curso normal sobrevive à custa do barateamento das contratações" (SILVA; BORGES, 2019, p. 149).

De lá para cá, o capítulo da LDB que trata desse assunto sofreu várias 


\section{ATOS DE \\ PESQUISA \\ EM EDUCAÇÃO}

ISSN: 1809-0354

5

modificações, mas a proposta inicial de formar professores em nível superior, pelo menos para aqueles que atuam na educação infantil e anos iniciais do ensino fundamental ( $1^{\circ}$ aos $5^{\circ}$ anos), não se concretizou, pois tem-se admitido (BRASIL, 2013) e reafirmada (BRASIL, 2017) a formação em nível médio, na modalidade normal para o exercício nos níveis citados (GATTI et al., 2019). Com relação às demais licenciaturas que formam professores para as áreas disciplinares, apesar de a Resolução CNE/CP 2/2002 (BRASIL, 2002) propor um projeto curricular que conciliasse formação específica com a pedagógica representando, portanto, um avanço no campo das políticas de formação de professores no Brasil (LIMA; AZEVEDO, 2019), na prática isso não aconteceu.

Com a aprovação da Resolução CNE/CP 2/2015, surge um novo projeto de formação de professores o qual foi bem visto pela comunidade acadêmica pela ênfase na "[...] justiça social, com respeito à diversidade e promoção da participação e da gestão democrática" (GATTl et al., 2019, p. 69), mas nem tanto pelos grupos ultraconservadores tais como o Movimento Brasil Livre (MBL) e o Escola Sem Partido, por exemplo (LIMA; AZEVEDO, 2019), assim como pelos mantenedores dos grandes grupos de universidades de ensino superior privadas. Por esse motivo, apesar de boa parte da Universidades públicas ter adequado suas matrizes curriculares a esse novo dispositivo legal, em face às pressões de grupos opositores às mudanças propostas para formação de professores, essa Resolução teve duas prorrogações e, com o agravamento das tensões que marcaram as políticas curriculares em razão da aprovação da Lei no 13.417/2017 (BRASIL, 2017), acabou sendo revogada no final de 2019 com a aprovação de uma nova resolução que ainda não foi implantada, mas certamente representará um retrocesso no campo das políticas de formação de professores no Brasil.

Em síntese, as fragilidades observadas nos cursos de licenciatura não se justificam apenas pelas suas condições de expansão, mas pela permanência de um currículo basicamente inalterado que, mesmo diante das diversas reformas educacionais, continua sendo "genérico", preparando ao mesmo tempo professores de Educação Infantil, Ensino Fundamental, especialistas em educação, diretores e supervisores (BARRETTO, 2015). Com relação à formação de professores para as áreas licenciadas, o cenário não tem sido diferente, pois o que se tem observado é 


\section{ATOS DE \\ PESQUISA \\ EM EDUCAÇÃO}

ISSN: 1809-0354

6

que as tentativas de avanços acabam sendo suprimidas por projetos que atendem muito mais aos interesses econômicos do que uma política pública de formação de professores com foco na qualidade da educação ofertada.

\subsection{Formação inicial do CP e o seu papel como formador docente}

O CP é, antes de gestor, um professor cuja formação inicial deu-se em cursos de licenciaturas ou em Pedagogia. Contudo, a Pedagogia, assim como as demais licenciaturas, priorizam a formação de professores e não de gestores o que inclui o CP. No caso das áreas licenciadas isso é compreensível, em razão de suas diretrizes, mas não é aceitável para o curso de Pedagogia que, em tese, é o responsável pela formação de gestores da educação e da escola e, portanto, do CP.

Com relação a esse assunto, Miranda e Veraszto (2014) afirmam que o modelo de formação adotado pelas Instituições de Ensino Superior (IES) não consegue aprofundar questões relativas à organização da escola sob o ponto de vista políticopedagógico e administrativo. Ao contrário, existe a prevalência do aprofundamento de estudos reflexivos voltados à formação política e humanística de futuros pedagogos(as) e para o exercício da docência em sala de aula em detrimento da gestão educacional.

A princípio, esse cenário é preocupante porque quando observamos o trabalho dos gestores (diretores e coordenadores pedagógicos) na rotina das escolas, percebe-se que cada um desses profissionais possui funções específicas que se complementam. Assim, diante do grau de complexidade da gestão das escolas, é necessária uma formação complementar, e, nesse caso, referimo-nos à formação teórica, em relação à formação inicial, além da importância de ser, antes de tudo, um docente e ter experiência profissional para assumir cargos ou funções de gestão, diante do caráter político-pedagógico apresentado no contexto da atualidade e da prática do gestor educacional (GRACINDO, 2009; MIRANDA; VERASZTO, 2014). Entretanto, não há consenso se o gestor (CP) tem de ser formado em Pedagogia, pois há um entendimento de que qualquer professor pode assumir a função de gestão da escola, há consenso de que o PC é responsável pela formação continuada dos professores (IMBERNÓN, 2010; PLACCO, SOUZA, 2011).

Em face ao exposto, a atuação do CP volta-se para a formação continuada em 


\section{ATOS DE \\ PESQUISA \\ EM EDUCAÇÃO}

ISSN: 1809-0354

serviço, centrada na escola, contribuindo para a reflexão sobre as ações pedagógicas e as dificuldades que percebem no seu trabalho, promovendo condições para 0 avanço dos professores, tornando-os autores de suas próprias práticas (GRACINDO, 2009).

O CP, ao assumir o papel de formador, bem como articulador do trabalho pedagógico coletivo, precisa ter ciência de que a atividade do coordenador-formador apresenta a complexidade de qualquer ação que defende e objetiva o crescimento e a construção da autonomia pedagógica dos profissionais com os quais desenvolve suas funções. Bruno (2009) acrescenta que ao CP compete articular e mobilizar a equipe escolar para elaborar, desenvolver e avaliar o Projeto Pedagógico, sempre com o apoio da equipe gestora e pedagógica da escola.

É possível afirmar que o processo de formação centrada na escola ocorre quando do contexto de trabalho emergem possibilidades diferenciadas de ação coletiva, proporcionadas pela socialização profissional. Quando a organização do cotidiano escolar permite o encontro dos professores para socializar as experiências profissionais e dialogar sobre os processos de aprendizagem dos estudantes, a escola se torna uma "instituição aprendente", representando um espaço privilegiado de aprendizado também daqueles que têm a função de ensinar. Nesse caso, professores e também o coordenador aprendem e se formam quando planejam suas ações, quando propõem alternativas para o trabalho, quando avaliam suas interlocuções com o intuito de redimensioná-las (CAMPOS; ARAGÃO, 2012). É dessa maneira que o papel do coordenador pedagógico, como principal formador do professor, se faz indispensável, pois conhece a escola, os sujeitos e seus principais dilemas (FRANCO; GONÇALVES, 2013).

\subsection{Formação centrada na escola}

A formação centrada na escola não substitui a formação inicial, ao contrário, elas se complementam. É oportuno salientar que apesar de esse modelo de formação, ou seja, a formação continuada, não se configurar em políticas públicas de formação de professores, é uma ação que contribui para o desenvolvimento profissional docente, assim como se constitui em um trabalho que parte do itinerário formativo dos professores e volta a eles em uma relação dialética, em que "[...] a reflexão crítica 


\section{ATOS DE \\ PESQUISA \\ EM EDUCAÇÃO}

ISSN: 1809-0354

8

sobre a prática se torna uma exigência da relação teoria/prática sem a qual a teoria pode ir virando blá-blá-blá e a prática, ativismo" (FREIRE, 2015, p. 24). Para dar conta dessa empreitada, o PC precisa ter claro que sua principal função é garantir um processo de ensino e aprendizagem saudável e bem-sucedido para os estudantes.

Considerando-se que os professores são os responsáveis pelo processo de ensino dos estudantes, em decorrência disso, são profissionais que necessitam de formação atualizada e constante. Em razão disso, na escola, o CP torna-se, por excelência, o profissional responsável pela formação continuada dos professores.

Essa formação é contínua e contextual, pois cada escola tem realidade própria requerendo um plano de ação formativo coerente com as necessidades da escola. Ademais, é preciso considerar que os professores têm conhecimentos e tempos de experiências distintos demandando do CP estratégias diferenciadas para o êxito da formação. Isso implica, por exemplo, partir da realidade dos professores, de uma situação real de ensino e de aprendizagem e da perspectiva de um professor como sujeito do processo formativo, pois, "[...] na formação deve-se trabalhar com os professores e não sobre eles" (IMBERNÓN, 2010, p. 26).

Formar professores é trabalhar os saberes e as práticas em vários níveis e situar os pontos em que podem se articular as lógicas que são heterogêneas. Assim, não está em jogo apenas uma relação de eficácia e de eficiência, mas a construção de uma identidade profissional (COSTA; ANDRADE, 2016).

Entretanto, colocar em prática uma ação formativa em uma escola como a Rede SESI/SP de Ensino, por exemplo, não é uma tarefa fácil, pois em determinados momentos, o CP é compelido a responder por necessidades do contexto escolar que não são de sua responsabilidade. Comumente, são questões que, apesar de fazerem parte da dinâmica da escola, não podem ser consideradas inerentes à função do CP. Isso não significa que o CP não possa colaborar com a direção da escola, ao contrário, ele é o mediador da relação entre o diretor e o conjunto de professores, mas as atividades de caráter técnico-burocrático não podem sobrepor as de caráter formativo.

A formação continuada não é desvinculada da formação inicial, pois constituem um mesmo processo que é contínuo e interligado, mas tem sido uma prática cada vez mais recorrente nas escolas em razão de fragilidades ainda presentes na formação inicial corroborando a atuação do CP. Por esse motivo, tem surgido projetos 


\section{ATOS DE \\ PESQUISA \\ EM EDUCAÇÃO}

ISSN: 1809-0354

9

inovadores similares aos mapeados em pesquisas internacionais (GATTI et al, 2019).

Na perspectiva dessas autoras, trata-se de experiências que:

evidenciam preocupação e ações direcionadas ao conhecimento pedagógico do conteúdo; desenvolvem estratégias formativas em que o professor tem papel ativo; valorizam a participação coletiva; estabelecem conexão com os contextos e com as políticas vigentes, e, mantêm-se por um período prolongado (GATTI et al., 2019, p. 268-269).

Nota-se, portanto, que a formação continuada docente está alinhada às políticas públicas vigentes, colaborando com o desenvolvimento profissional docente. Contudo, apesar da importância da formação continuada, cujos avanços são visíveis, o país ainda carece de políticas públicas de formação inicial, pois caso contrário, teremos de investir cada vez mais em formação continuada.

\section{MÉTODO}

Dados os objetivos desta pesquisa, optou-se pela abordagem qualitativa porque esse método vem proporcionando, há várias décadas, grandes contribuições para o avanço do conhecimento em educação.

Os sujeitos participantes da pesquisa foram 8 professores da Rede SESI-SP de Ensino de uma das unidades do município de Santo André-SP a qual foi selecionada por sorteio. Como um dos autores atua como CP em uma das unidades de ensino do SESI, essa unidade foi excluída do sorteio com o intuito de evitar eventuais vieses de pesquisa.

Com relação ao perfil dos participantes, dos oito entrevistados, sete são do gênero feminino e um do masculino. O tempo de trabalho na rede SESI-SP de ensino desses professores variou entre dois e 23 anos; e a idade, de 29 à 54 anos. Em relação à graduação, perceberam-se formações distintas, como: Artes, Letras, Química, Biologia, Filosofia e Pedagogia. Justifica-se esse fato devido aos docentes lecionarem para diferentes faixas etárias, do Ensino Fundamental I até o Ensino Médio.

Os dados foram obtidos por meio de entrevista semiestruturada realizada com professores que concordaram participar da pesquisa, no período de fevereiro a março de 2019. As respostas foram organizadas, classificadas e categorizadas 


\section{ATOS DE \\ PESQUISA \\ EM EDUCAÇÃO}

ISSN: 1809-0354

considerando-se a semelhança entre elas (BARDIN, 2006).

Para garantir o sigilo acerca da identidade dos participantes, foi utilizada a letra "P" para professor (a) e um número para diferenciá-los. Contudo, cumpre destacar que todos os professores estavam à vontade durante as entrevistas fazendo com que pudessem expressar suas concepções sobre o tema da pesquisa bem à vontade, pois Ihes foi garantido o anonimato.

\section{CRIANDO CATEGORIAS}

Partindo-se do pressuposto de que a categorização diz respeito a colocar cada elemento em um grupo comum a ele (BARDIN, 2006), nesta pesquisa as categorias estão atreladas ao agrupamento das indagações durante a entrevista os quais trazem respostas bastante similares. Contudo, nesse artigo, em razão de sua dimensão, estão apresentadas apenas três categorias quais sejam: concepção de educação, parceria entre $\mathrm{CP}$ e professores e troca de experiência docente.

\subsection{Concepção de formação no espaço escolar}

Essa categoria examina as concepções sobre educação para ilustrar possibilidades de defender mais de uma visão dentro da mesma concepção ou, ainda, uma outra concepção. Afinal, não há a concepção de ensino, mas algumas visões do que pode ser entendido como educação. Nesse sentido, Mizukami (2013) entende que o professor exerce uma atividade complexa que possui especificidades que, de alguma forma, precisam ser aprendidas.

Os professores trouxeram algumas concepções acerca da educação de modo implícito a seu discurso. Em termos mais abrangentes, esse discurso privilegia a centralidade do estudante no processo de aprendizagem. Isso coaduna com os trabalhos formativos da própria rede SESI-SP e com a formação pregressa do professor. Contudo, cabe algumas observações.

Não há presente nos depoimentos a opção de ver o estudante como um ator dentro de um processo social que traz formações prévias para além do ambiente escolar. A alusão de pensar no estudante fora da escola, no que se refere a seus 


\section{ATOS DE

saberes, traz a preocupação de entender como é construído o idioleto ${ }^{1}$ de uma sala ou de uma geração a partir dos signos que compreendem seu universo significativo os quais extrapolam o ambiente escolar. Essa preocupação não está presente nas falas dos professores, e isso pode denotar o recorte e o enfoque que podem estar presentes nas formações deles.

É possível perceber que pouco se tenta modular uma aula para o "idioma" da sala. Muitas vezes, uma palavra ou uma expressão só tem significado para um grupo de estudantes, uma sala ou uma faixa etária. Compreender quais são os signos que trazem identidade aproxima os estudantes do professor e podem transformar 0 processo de aprendizagem.

A preocupação de entender a linguagem que os estudantes constroem fora da sala de aula - mas que preenchem o ambiente escolar - foi pouco evidenciada no que se refere às temáticas dos encontros formativos. Contudo, outra temática teve destaque nas falas dos professores - a de se preocupar com a adequação entre o conteúdo com as dificuldades individuais do estudante.

Os professores destacaram a preocupação em adequar a matéria à realidade do estudante. No entanto, o termo realidade aqui tem um sentido bem estrito: a realidade cognitiva. Grupos de estudantes estão em momentos diferentes de aprendizagem e demandam ora explicações mais complexas, ora explicações menos complexas. Ao que parece, os encontros formativos deram conta de destacar a questão de adaptar a matéria à dificuldade do estudante.

Nesse sentido, há o acompanhamento do processo de aprendizagem do estudante, a palavra educação, não por acaso, vem ao encontro do sentido do presente trabalho, ela guarda relação com o termo latim ducere, que significa, por exemplo, conduzir. Freire (2015) aponta que a condução pode ser, sobretudo, humanizada, permitindo-se agir como aquilo que se é: sonhadores, capazes de amar e também odiar, de realizar e também de errar, como humanos, de pensar:

\footnotetext{
Nenhuma formação docente verdadeira pode fazer-se alheada, de um lado, do exercício da criticidade que implica a promoção da curiosidade ingênua à curiosidade epistemológica, do outro sem o reconhecimento do valor das emoções, da sensibilidade, da afetividade, da intuição ou adivinhação (FREIRE, 2015, p. 45-46).
}

\footnotetext{
${ }_{1}^{1}$ Diz respeito ao modo particular como cada falante usa a língua, segundo os seus hábitos discursivos, variações geográficas, características sociais etc.
} 


\section{ATOS DE

É interessante refletir que as noções de educação compreendem visões tradicionais que são entendidas como um conjunto de saberes adquiridos formalmente (formação inicial) ou uma visão de que esse processo de formação se insere em uma perspectiva de que está sempre inacabada (formação continuada). As instituições de Ensino Superior, como afirmam Gatti, Barreto e André (2011), parecem ter agravado a questão da formação docente ao relegar o papel da formação de professores como um anexo do bacharelado. Uma disciplina de didática ao final do curso não dá conta de problematizar a vivência anterior que o aluno teve em sua formação básica. Em certa medida, a experiência como aluno forma o professor que se será.

Ora, se incentiva-se o professor a sempre se atualizar e refletir sobre a sua prática, é preciso que o CP igualmente faça o mesmo. Placo (2003) orienta que, assim como o docente, o CP deve cuidar também de sua própria formação contínua, o que pode ser problemático uma vez que essa formação geralmente é feita de maneira autônoma.

Ainda em relação à concepção de educação, não havendo receita didática absoluta, é preciso sempre se adequar ao contexto. Essa adequação vem centrada na figura do aprendizado da criança como objetivo comum da formação como descrito nesta entrevista:

\footnotetext{
"Um sonho seria que houvesse mais formações focadas realmente no interesse total e absoluto da tática do professor para com o aprendizado da criança, isso seria fantástico. Algumas formações vêm prontas e infelizmente nem sempre conseguimos colocar em prática na realidade. É utopia pensar que daria. Mas vamos adaptando daqui adaptando dali" (P5).
}

Uma vez que se entende que a educação, apesar de ter uma base referenciada em um núcleo de valores, ela vai se amalgamando com novas experiências continuamente. A forma na qual quer se compor a própria formação precisa estar nítida para que os professores não se orientem em direção oposta àquilo que acreditam ou sobre um referencial que não estão inseridos. No caso do SESI-SP, há essa preocupação, pois, a concepção de educação

[...] engloba o ensino, a aprendizagem e a pesquisa a partir de uma abordagem sociointeracionista, que considera o conhecimento como um processo de construção fundado no diálogo permanente entre professores e estudantes (SESI-SP, 2016, p. 28). 


\section{ATOS DE \\ PESQUISA \\ EM EDUCAÇÃO}

ISSN: 1809-0354

13

Tal visão de ensino e aprendizagem do Serviço Social da Indústria de São Paulo coaduna com a visão de que o ensino, apesar de partir do diálogo, está em constante processo de adequação às realidades locais, que podem ser materializadas na dificuldade de aprendizagem em diferentes graus. Identificar essas dificuldades permite que o CP auxilie o professor a "olhar aquilo que o aluno não compreende $e$ tentar encontrar uma solução para a defasagem na aprendizagem" (Professora 7). Essa professora, ao destacar as necessidades particulares de cada aluno, revela a ligação da concepção de educação, que gira em torno desse processo de construção do conhecimento do aluno, como uma preocupação constante na sua prática e igualmente a importância do papel do CP.

Nas entrevistas realizadas, notou-se que o fato do CP conduzir os assuntos nos encontros formativos pautando-se nos Referenciais Curriculares da Rede SESI e, consequentemente, atrelar as temáticas à concepção de educação da rede, torna-os mais significativos, uma vez que, ao planejarem as aulas, os professores devem obrigatoriamente seguir a concepção adotada e alinhar as atualidades a elas. $O$ Professor 2 afirmou, com relação aos encontros formativos e o atendimento das necessidades docentes:

"Como o Sesi é uma rede grande, tem seu material próprio e uma concepção própria também, precisa normalizar os processos pedagógicos em todas as unidades. Entendo que os encontros formativos que têm esta finalidade de formar os professores nos princípios que o SESI trabalha, atendem às necessidades dos professores" (P. 2).

\subsection{Parceria entre CP e professores}

A segunda categoria versa sobre a parceria entre coordenador pedagógico e professores. Levando em consideração, como afirmam, Canário (2006), Placco e Souza (2010) e Gracindo (2009), que o CP tem como função auxiliar na formação docente levando em conta que o universo de professores que ele atende são de diversas áreas e de distintas formações, é preciso que o CP tenha a possibilidade de reconhecer as particularidades de cada professor. Quando os professores foram indagados sobre a possibilidade de escolherem entre a autoformação ou a formação orientada pelo $\mathrm{CP}$, foram unânimes em atribuir o apoio do CP a um papel de parceria. 


\section{ATOS DE

"Eu optaria pela formação feita pela coordenadora escolar por dois motivos: um é que eu não tenho tempo para fazer cursos fora, pois trabalho em período integral e quando estou em casa tenho trabalhos escolares para corrigir e planejar. O outro [motivo] é que a coordenadora já planeja as formações levando em conta quais são as minhas dificuldades, é um direcionamento mais personalizado do que quando faço formações fora. Ela já aborda temas que sabe que eu preciso desenvolver, como faço com os meus alunos: para cada nível de aprendizagem proponho atividades específicas" (P. 8).

A professora citada destaca a importância de orientações personalizadas. Ocorre com frequência o peso de jornada dupla e outras responsabilidades oriundas da vida pessoal do docente que não permite o espaço para autoformação. Assim, sem abrir mão da formação continuada com base na concepção de educação, o professor tem o CP como um grande parceiro nesse processo formativo como facilitador competente. Essa possibilidade de parceria é construída na consolidação de um ambiente em que haja uma troca mútua entre os docentes e o CP. Essa permuta favorece o seu papel de formador de docentes, como ilustra a Professora 3 a seguir:

"O que favorece é o trabalho junto, de parceria. No momento que nós temos o coordenador pedagógico como parceiro para nos auxiliar na rotina, nas dificuldades. Sinto que é essencial poder ter um diálogo aberto e dar ideias ou trazer sugestões para gente ir pensando junto" ( $P$. 3).

É relevante ver que o CP acaba por ter um papel de problematizador da prática, no sentido de possibilitar a construção de uma autoconsciência da prática do professor. A Professora 3 não destaca as respostas prontas, o CP não traz conteúdos para que os professores absorvam, mas compartilha entendimentos e questões sobre a prática que, situadas no contexto local, fortalecem a parceria entre $\mathrm{CP}$ e docentes.

A característica principal dessa parceria dá-se no assentamento da posição de que o objetivo do professor e do CP são os mesmos, a saber: formar o aluno segundo a concepção do SESI-SP. Nesse sentido, reconhecer que o objetivo das funções escolares esteja centrado no aluno estabelece uma conexão de parceria entre CP. Corroborando a posição destacada de parceria, a Professora 7 afirma:

\footnotetext{
"As formações do SESI acrescentam no meu dia a dia na minha prática pedagógica, pois abordam temáticas de acordo com a linha de ensino oferecida. Um dos assuntos em uma das reuniões que achei muito importante foi a questão da gestão da sala de aula. Eu até comprei um livro para poder estudar um pouquinho mais. Então, acho que refletir sobre a prática é muito importante e valioso. Às vezes eu percebo a resistência por parte de alguns profissionais de não aproveitar esse momento para um aperfeiçoamento e para que possamos fazer uma autocrítica" (P. 7).
} 


\section{ATOS DE \\ PESQUISA \\ EM EDUCAÇÃO}

ISSN: 1809-0354

Em tempo, a Professora 7 destaca que é preciso também a predisposição do professor, sem ela, mesmo dado o objetivo comum, a formação torna-se uma impossibilidade. O professor precisa estar aberto a fazer a autocrítica como um momento de aprimoramento profissional. A formação do CP está ligada à formação do professor. Nesse sentido, Mizukami (1996) orienta que, na formação continuada, existem inúmeros atores, dentre professores, comunidade, estudantes e os próprios meios de comunicação que devem ser articulados a fim de fortalecer o papel da docência como alguém de destaque na organização da complexidade que emerge na realidade da sala de aula cotidianamente.

Essa categoria ajuda a revelar o objetivo em comum e, a partir dela, estabelecer a parceria entre professor e CP. Assim como o professor assume, em um ambiente de protagonismo do estudante, o papel de mediador em sala de aula, o CP assume, em formações e no dia a dia, o papel de mediador de saberes e de experiências dos docentes. Como vimos, vários professores elencaram a importância do CP em destacar pontos que na cotidianidade são normais e acabam passando batido. Isso demonstra que a observação do $\mathrm{CP}$, orientada desde uma perspectiva externa, pode ser trabalhada como fonte rica de reflexão sobre a prática. Pôde-se ver os professores destacarem essa peculiaridade do trabalho da CP. Dessa forma, a visão de que a CP tem esse papel de mediador e problematizador de experiências desloca a reflexão para a terceira categoria - a troca de experiência entre docentes.

\subsection{Troca de experiência docente}

A terceira categoria denota de porte da noção de que $\mathrm{CP}$ e professor são parceiros, que o que há de mais rico no dia a dia escolar são as boas práticas. Tardif (2002) afirma que o professor é um produtor de saberes. Nesse sentido, existem práticas que podem ser aplicadas a qualquer área do conhecimento e existem outras que são restritas a determinadas áreas do conhecimento ou faixa etária. Essa dificuldade é abordada pela Professora 1:

"E para ser mais franca, penso que perdemos tempo em trabalhar questões, por exemplo, da inclusão - que não dizem muito ao meu respeito. Deixamos de trabalhar assuntos relacionados ao meu trabalho, em outros encontros percebi que muitas coisas discutidas são direcionadas para o Fundamental I, exemplo: como lidar com crianças numa faixa etária bem menor que a 


\section{ATOS DE

que eu trabalho. [A faixa etária que trabalho] tem aspectos relacionados à mudança hormonal (...), do tipo de carreira [que vai seguir], [do vestibular que vai] prestar, dos conflitos tem, e eles estão à margem para lidar com isso, né?" (P. 1).

O valioso tempo de formação acaba por perder oportunidades quando abre mão de tratar assuntos específicos de área ou faixa etária. Um dos grandes avanços na questão educacional foi a criança ser vista com processos cognitivos específicos e demanda de desenvolvimento específicos.

O CP pode dispor esses grupos por área de interesses, pois tem uma visão privilegiada das nuances e dos agrupamentos de área e faixa etária. Assim, por competência e posicionamento, torna-se responsável por organizar tal troca de experiência entre docentes. Nesse sentido, afirma a professora que os encontros dessa natureza "[...] ajudam bastante, principalmente no momento em que posso fazer trocas com outros profissionais e ver que não estou sozinha" (Professora 7). A professora destaca um aspecto emocional que envolve o acolhimento entre os próprios professores no reconhecimento de questões e assunção de desafios. Essa perspectiva de agrupamento é considerada favorável, pois, ao descrever a experiência dos professores, Fiorentini (2013, p. 13) afirma que os docentes que

[...] participaram de comunidades investigativas apresentam evidências concretas de que a pesquisa sobre suas práticas, mediada pela interlocução com os membros dessa comunidade e por teorias relativas às respectivas questões de investigação, exerceu papel fundamental na compreensão e transformação das práticas pedagógicas e na constituição de suas profissionalidades com postura investigativa.

O autor designa como comunidade investigativa a prática coletiva e sistemática de organizar troca de experiências com fins de extrair de cada encontro as ações que tiveram êxito em cada contexto educacional. Muitas vezes, a formação, quando feita de maneira menos personalista e generalista, enfrenta uma perda de sentido em comparação àquela feita em contextos em que existem trocas de experiências. Essa posição é reiterada pela Professora 8:

"Os assuntos abordados podem até ser importantes, mas vídeos longos com especialistas
muitas vezes não trazem a realidade da escola. Quando o encontro aborda um tema [proposto
pelo] coordenador é mais produtivo, principalmente quando podemos trocar experiências entre
os pares - mostrar o que deu certo ou não em nossa sala de aula e ouvir as experiências dos
outros professores" (P. 8).
É importante frisar que não há prática perfeita, muitas vezes ela não é adequada a um contexto de sala diferente daquele em que foi extraído, bem como ao 


\section{ATOS DE

perfil do professor. Ajudar os docentes a reconhecer as adequações necessárias às práticas que lhe inspiraram de alguma forma no ambiente da comunidade investigativa é algo que pode ser facilitado pelo CP. Mesmo assim, a questão da importância das trocas de experiência é frequente nas entrevistas, mas isso exige um mapeamento mais específico do quadro docentes em agrupamentos. Se a troca de experiência não é organizada, acaba tendo um efeito contrário. Nessa perspectiva, a Professora 8 sugere que os encontros formativos

"[...] fossem propostos por área do conhecimento para que pudéssemos conversar com as disciplinas afins, e aí trocar ideias, propor projetos integrados e refletir sobre estratégias específicas para a área. Quando os encontros são com toda a equipe, muitas vezes os assuntos não fazem parte da realidade da minha sala ou da minha disciplina, e isso desestimula o interesse e a participação" (P. 8).

A questão do estímulo e sensibilização dá-se em especial pelo agrupamento em áreas e faixas etárias para discutir as questões mais especificas e abordar as correlações entre áreas. Igualmente, se as questões e os desafios são os mesmos, eles podem ser abordados da mesma forma. Convencionou-se a sala de aula como um espaço de diálogo e de troca; assim, um encontro formativo deve ter o mesmo sentido - é o que destaca a Professora 6 ao fazer a analogia entre as formações e as dinâmicas feitas em sala de aula:

"Quando penso em encontro formativo, vejo como uma sala de aula, com agrupamentos produtivos. Acho que os encontros que promovem trabalhos em grupo, onde podemos analisar casos e trocar opiniões em conjuntos são muito mais atrativos e agregadores" (P. 6).

Tal analogia é rica e já foi abordada aqui, do CP mediador. Não é à toa que o ambiente da sala de aula já foi trabalhado e repensado inúmeras vezes e, hoje, se tem, mais ou menos como status quo, a visão de que ambientes onde há mais diálogo são ambientes melhores para o aprendizado, apesar de não ser unanimidade - até porque isso não é garantia de que seja algo bom; a dificuldade em fornecer-se um ambiente propício para o diálogo é o desafio.

O trocar ideia remonta um aspecto informal, em que as pessoas se agrupam por afinidades entre elas ou entre temas. É por isso que os encontros formativos buscam, muitas vezes, em um primeiro momento de uma sensibilização, algo que aproxime os docentes - e não certo de que isso trará um ambiente de liberdade 


\section{ATOS DE \\ PESQUISA \\ EM EDUCAÇÃO}

ISSN: 1809-0354

18

necessária para o diálogo. É precioso o agrupamento por temas e interesses que serão sensíveis às demandas dos docentes e da própria rede.

É um desafio para o CP conseguir juntar grupos diversos e distintos em suas afinidades e interesses; contudo, o caminho que parece ser mais promissor é aquele que consegue aliar a diferença para não insurgir o mais do mesmo, com a igualdade. Por exemplo, agrupar professores de humanas para uma questão pertinente à área; ou, em uma temática mais geral, diversificar a formação dos integrantes da comunidade de investigação.

Viu-se que os docentes se preocupam com a pertinência das formações com suas preocupações individuais. Com isso, é necessário definir muito bem o objetivo da formação, caso contrário os CP poderão não obter êxito em sua prática formativa.

\section{CONSIDERAÇÕES FINAIS}

Com base no desenvolvimento deste estudo que investigou as concepções de professores da Rede SESI-SP de Ensino acerca da formação desenvolvida pelo CP, podemos afirmar que a maioria dos achados denotam o entendimento de que esse profissional desenvolve um trabalho focado nas orientações curriculares dessa rede de ensino e coerente com as expectativas de formação da maior parte dos participantes da pesquisa. Os pontos divergentes estão alinhados com a dificuldade de o CP articular práticas formativas com os pressupostos institucionais, expectativas dos professores em um espaço caracterizado pela diversidade (SOUZA, 2006).

Em termos mais específicos alguns professores consideram que as práticas formativas não cumprem suas intencionalidades porque em certos momentos elas focam em assuntos mais amplos e não nas áreas de ensino de cada professor. Eles consideram que isso ocorre porque trata-se de uma rede de ensino grande que preza pela "normatização" das práticas pedagógicas e, por esse motivo, as formações vêm prontas impedindo, por vezes, de serem colocadas em práticas, mas esses mesmos professores reconhecem que $\mathrm{O} \mathrm{CP}$ se esforça para adequar essas práticas às necessidades deles.

Foi constatado ainda consenso entre os professores acerca da necessidade de haver formação continuada sob a responsabilidade do $\mathrm{CP}$, mas não existe a 


\section{ATOS DE \\ PESQUISA \\ EM EDUCAÇÃO}

ISSN: 1809-0354

possibilidade de haver um projeto de autoformação porque as demandas de sala de aula são muitas. Ademais, na concepção dos entrevistados, se a formação fosse individualizada poderia haver prejuízos no processo de implementação do currículo da Rede SESI-SP de Ensino. Quanto à parceria entre CP e professores, o entendimento é que há uma relação de respeito e cumplicidade que reverbera na melhoria da prática docente.

Por fim, com relação às trocas de experiências, os depoimentos convergem para o que foi apontado na primeira categoria e, portanto, não caminham na mesma direção. Assim como boa parte dos professores reconhecem a importância da troca de experiência, questionam que nem todas as reuniões formativas favorecem o diálogo entre os professores. Isso ocorre porque o grupo professores é grande, alguns temas não são relativos aos níveis de ensino que cada professor atua o que impede o desenvolvimento de comunidades investigativas (FIORENTINI, 2013).

Em face ao exposto, esses achados ratificam o entendimento de que o $\mathrm{CP}$, como gestor do processo de ensino e de aprendizagem é corresponsável pelo desenvolvimento do currículo e, consequentemente, pela busca da qualidade da educação nos termos de seus referenciais curriculares. Sua função precípua está centrada na formação continuada em serviço (BORGES; CARVALHO, 2020; CANÁRIO, 2006; GRACINDO, 2009; PLACCO, SOUZA, 2010), tornando os professores autores de suas próprias práticas (GRACINDO, 2009). Mas há o reconhecimento de que existe a possibilidade de o CP colaborar com a direção da escola numa perspectiva de articular a dimensão pedagógica com a administrativa desde que não perca o foco de sua atuação (GIGLIO, 2006).

\section{NONATO ASSIS DE MIRANDA}

Doutor em Educação pela Universidade Estadual de Campinas (Unicamp), Mestre em Educação pela Unniversidade São Marcos, licenciado em Pedagogia (Faculdades Integradas Campos Salles), Letras (FEMA) e Sociologia (Universidade Paulista). Coordenador do Programa de Pós-Graduação em Educação e Pró-Reitor de Inovação em Ensino da Universidade Municipal de São Caetano do Sul (USCS). Desenvolve pesquisas na área de educação básica com foco em gestão e políticas educacionais.

\section{FERNANDA DIAS GUILHERMONI}

Mestre em Educação pela Universidade Municipal de São Caetano do Sul (USCS); licenciatura em Pedagogia e especialização em Psicopedagogia Clínica e Institucional pela Universidade Metodista de São Paulo. Coordenadora Pedagógica do Serviço 


\section{ATOS DE \\ PESQUISA \\ EM EDUCAÇÃO}

ISSN: 1809-0354

20

Social da Indústria (SESI) - Diretoria Regional de São Paulo e professor do ensino superior.

\section{REFERÊNCIAS}

AZEVEDO, J.G; ALVES, N.G (orgs). Formação de Professores: possibilidades do imprevisível. Rio de Janeiro: DP\&A, 2004.

BARDIN, L. Análise de conteúdo. Lisboa: Edições 70, 2006.

BARRETTO, E. S. S. Políticas de formação docente para a educação básica no Brasil: embates contemporâneos. Revista Brasileira de Educação, Rio de Janeiro, v. 20, n. 62, p. 679-701, jul./set. 2015.

BRASIL. Lei de Diretrizes e Bases da Educação Nacional, Lei no 9.394, de 20 de dezembro de 1996. Brasília: Senado Federal, 1996.

BRASIL. Resolução CNE/CP n. 1, de 18 fev. de 2002. Institui DCN para a Formação de Professores da Educação Básica, em nível superior, Brasília-DF, 2002.

BRASIL. Lei no 12.796, de 4 de abril de 2013. Altera a Lei o 9.394/96 que estabelece as Diretrizes e Bases da Educação Nacional. Diário Oficial da União, Brasília, DF, 5 abr. 2013.

BRASIL. Resolução CNE/CEB n. 2, de 1ำ de julho de 2015. Define as Diretrizes Curriculares Nacionais para a formação inicial em nível superior...Brasília-DF, 2015.

BRASIL. Lei no 13.415, de 16 de fevereiro de 2017. Diário Oficial da União, Brasília, DF, 17 fev. 2017.

BRUNO, E. B. G. et al. (Org). O Coordenador Pedagógico e a formação docente. 10. ed. São Paulo: Loyola, 2009.

CAMPOS, P. R. I.; ARAGÃO, A. M. F. O CP e a formação docente: possíveis caminhos. In: PLACCO, V. M. N. S.; ALMEIDA, L. R. (orgs.). O coordenador pedagógico: provocações e possibilidades de atuação. São Paulo: Loyola, 2012. p. 37-56.

CANÁRIO, R. A escola tem futuro? Das promessas às incertezas. Porto Alegre: Artmed, 2006.

COSTA, C. C.; ANDRADE, M. F. R. Formação docente e políticas públicas: uma visão histórica. Revista Ciências Humanas, Educação e Desenvolvimento Humano, Taubaté, v. 9, n. 1, p. 48-61, jun. 2016.

DISTRITO FEDERAL. Lei № 4.751 , de 7 de fevereiro de 2012. Dispõe sobre o 


\section{ATOS DE \\ PESQUISA \\ EM EDUCAÇÃO}

ISSN: 1809-0354

21

Sistema de Ensino e a Gestão Democrática do Sistema de Ensino Público do Distrito Federal. Brasília: Poder Executivo, [2012]. Disponível em: https://bit.ly/2YWG08I.

Acesso em: 20 fev. 2019.

FRANCO, M. J. N.; GONÇALVES, L. S. M. Coordenação pedagógica e formação de professores: caminhos de emancipação ou dependência profissional. Psicol. da Educ., São Paulo, v. 37, 2013, p. 63-71.

FREIRE, P. Pedagogia da autonomia: saberes necessários à prática educativa. Rio de Janeiro: Paz e Terra, 2015.

FIORENTINI, D.; LORENZATO, S. Investigação em educação matemática: percursos teóricos e metodológicos. Campinas: Autores Associados, 2006.

FIORENTINI, D. Aprendizagem profissional e participação em comunidades investigativas. In: ENCONTRO NACIONAL DE EDUCAÇÃO MATEMÁTICA, 11., 2013, Curitiba. Anais eletrônicos [...]. Curitiba: PUC, 2013. Disponível em: http://sbem.iuri0094.hospedagemdesites.ws/anais/XIENEM/pdf/2988_2195_ID.pdf. Acesso em: 10 jan. 2019.

GARRIDO, E. Espaço de formação continuada para o professor-coordenador. In: BRUNO, E. B. G.; ALMEIDA, L. R. de; CHRISTOV, L. H. S. (orgs.). O coordenador pedagógico e a formação docente. 9. ed. São Paulo: Edições Loyola, 2008. p. 9-15. GATTI, B. A.; BARRETTO, E. S. S.; ANDRÉ, M. E. D. A. Políticas docentes no Brasil: um estado da arte. Brasília: UNESCO, 2011.

GATTI, B. A. et al. Professores do Brasil: novos cenários de formação. Brasília: Unesco, 2019.

GRACINDO, R. V. O gestor escolar e as demandas da gestão democrática:

exigências, práticas, perfil e formação. Retratos da Escola, Brasília, v. 3, n. 4, p. 135147, 2009.

IMBERNÓN, F. Formação continuada de professores. Porto Alegre: Artmed, 2010. JAWORSKI, B. Building and sustaining inquiry communities in mathematics teaching development: Teachers and Didacticians in Collaboration. In: International handbook of mathematics teacher education: Vol. 3, 2008. p. 309-330.

LIBÂNEO, J. C. Pedagogia e pedagogos, para quê? São Paulo: Cortez, 1998.

LIMA, A. M. S.; AZEVEDO, M. L. N. Processo de institucionalização da política nacional e estadual de formação docente: proposições e resistências no Paraná. Educação \& Formação, Fortaleza, v. 4, n. 12, p. 124-147 set./out. 2019.

MIRANDA, N. A.; VERASZTO, E. V. A formação inicial do gestor educacional na região do Grande ABC Paulista. Revista @mbienteeducação, São Paulo, v. 7, n. 1, p. 166-178, jan./abr. 2014. 


\section{ATOS DE \\ PESQUISA \\ EM EDUCAÇÃO}

ISSN: 1809-0354

MIZUKAMI, M. G. N. Docência, trajetórias pessoais e desenvolvimento profissional. In: REALI, A. M. M. R.; MIZUKAMI, M. G. N. (orgs.). Formação de professores: tendências atuais. São Carlos: EDUFSCar, 1996.

MIZUKAMI, M. G. N. Aprendizagem da docência: professores formadores. Revista eCurriculum, São Paulo, v. 1, n. 1, p. 1-17, dez.jjul. 2005-2006.

MIZUKAMI, M. G. N. Escola e desenvolvimento profissional da docência. In: GATTI, B. A. et al. (orgs.). Por uma política nacional de formação de professores. São Paulo: Unesp, 2013. p. 23-54.

PEREIRA, J. E. D. As licenciaturas e as novas políticas educacionais para a formação docente. Educação e Sociedade, Campinas, v. 20, n. 68, p. 109-125, 1999.

PLACCO, V. M. N. S. O coordenador pedagógico no confronto com o cotidiano da escola. In: ALMEIDA, L. R.; PLACCO, V. M. N. (orgs.). O coordenador pedagógico e o cotidiano da escola. São Paulo: Loyola, 2003. p. 66-70.

PLACCO, Vera Maria Nigro de Souza; SILVA, Sylvia Helena Souza. A formação do professor: reflexões, desafios e perspectivas. In: BRUNO, E. B. G; ALMEIDA, L. R; CRISTOV, L. H. S. (ORG). O coordenador pedagógico e a formação docente. 13 ed. São Paulo: Edições Loyola, 2015.

PLACCO, V. M. N. S. Formação e prática do educador e do orientador: confrontos e questionamentos. Campinas, Papirus. 1994.

PLACCO, V. M. N. S.; SOUZA, V. L. T. O trabalho do coordenador pedagógico na visão de professores e diretores: contribuições à compreensão de sua identidade profissional. In: PLACCO, V. M. N. S.; ALMEIDA, L. R. de. (orgs.). O coordenador pedagógico: provocações e possibilidades de atuação. 2. ed. São Paulo: Loyola, 2010. p. 25-27.

PLACCO, V. M. N. S.; SOUZA, V. L. T. O coordenador pedagógico e a formação de professores: intenções, tensões e contradições. Relatório de Pesquisa. Fundação Victor Civita, fev. 2011.

PLACCO, V. M. N. S.; SILVA, S. H. S. A formação do professor: reflexões, desafios e perspectivas. In: BRUNO, E. B. G; ALMEIDA, L. R.; CRISTOV, L. H. S. (ORG). O coordenador pedagógico e a formação docente. 13. ed. São Paulo: Edições Loyola, 2015. p. 25-32.

POLON, T. L. P. Identificação dos perfis de liderança características relacionadas à gestão pedagógica eficaz nas escolas participantes do projeto Geres: Estudo Longitudinal Geração Escolar 2005. 2009. Tese (Doutorado em educação) - PUC do Rio de Janeiro, Rio de Janeiro, 2009.

SAVIANI, D. Formação de professores: aspectos históricos e teóricos do problema 

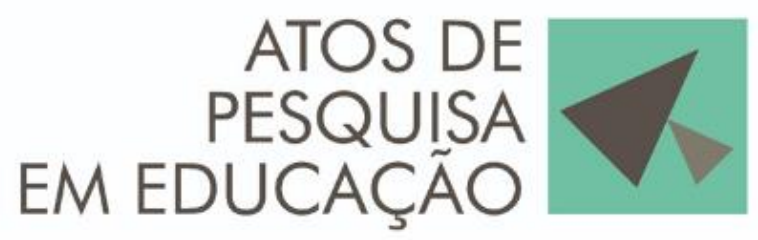

ISSN: 1809-0354

no contexto brasileiro. Revista Brasileira de Educação, v. 14, n. 40, p. 143-155, 2009.

SERPA, D.; LOPES, N. Os caminhos da coordenação pedagógica e da formação de professores. Revista Nova Escola - Gestão Escolar. Edição especial, Editora Abril, jun. 2011.

SESI-SP. Serviço Social da Indústria - São Paulo. Referencial curricular do Sistema SESI-SP de Ensino: ensino fundamental. São Paulo: SESI-SP Editora, 2016.

SILVA, F. T.; BORGES, L. F. F. O cenário da formação de professores no Brasil nos vinte anos da atual LDB. Debates em Educação, vol. 11, no. 25, p. 139-154, set./dez. 2019.

TARDIF, M. Saberes docentes e formação profissional. 4. ed. Rio de Janeiro: Vozes, 2002.

VAGULA, E. O professor, seus saberes e sua identidade. Rev. Cient. Fac. Lour. Filho, v. 4, n. 1, p. 103-116, 2005.

Recebido em: 01/12/2019.

Aprovado em: 01/06/2020. 